\title{
Endophytic Bacteria: Hidden Protective Associates of Plants against Biotic and Abiotic Stresses
}

\author{
Francisca I. OKUNGBOWA*, Hakeem O. SHITTU, \\ Henry O. OBIAZIKWOR \\ University of Benin, Department of Plant Biology and Biotechnology, Ugbowo, Benin City, Nigeria; \\ francisca.okungbowa@uniben.edu(*correspondingauthor); olalekan.shittu@uniben.edu; onyemaechi.obiazikwor@uniben.edu
}

\begin{abstract}
An endophyte is a microorganism, usually bacterium or fungus, which lives within the internal tissue of a host plant, causing no apparent harm. Some characteristics of an endophyte include ability to promote plant growth and to confer plant tolerance to biotic and abiotic stresses. Endophytic bacteria spread across many phyla including the Actinobacteria, Bacteroidetes, Firmicutes and Proteobacteria. Endophytic bacteria are recruited by hosts and they get attached to the surface and eventually find their way into the internal tissues where they spread to the intercellular spaces of host plants. These bacteria have been isolated and characterized from different plants. Currently, culture-independent methods such as sequencing of the $16 \mathrm{~S}$ rRNA gene or metalogenomics are used for identification and characterization of endophytes. The mechanisms by which the endophyte-induced plant protection is brought about can be through direct and/or indirect methods. The direct strategy antagonizes phytopathogens by the production of chemical substances while the indirect mechanisms improve resistance of hosts to pathogens. Global gene expression studies on some common endophytic bacteria implicated these direct and indirect strategies of bacterial-induced protection. More research should be geared towards how the economic importance of endophytic bacteria could be utilized to enhance global food security.
\end{abstract}

Keywords: bacteria; colonization; endophytes; gene - expression; protection; stress

\section{Introduction}

The word "endophyte" is derived from two Greek words, "endon" which means within, and "phyton" meaning plant (Kandel et al., 2017). An endophyte is a microorganism, mainly fungus or bacterium that lives inside plant's tissue and does no apparent harm to its host (Gao et al., 2010; Tamosiune et al., 2017; Lata et al., 2018). Some microbes may be currently considered endophytic, but this designation may be changed if they are subsequently shown to be harmful to a plant host (Cocq et al., 2017). According to Hardoim et al. (2015) endophytes are microbes including bacteria, archaea, fungi, and protists that colonize the plant interior regardless of the outcome of the association. An organism is considered an endophyte by possessing certain common characteristics which include living inside a host plant, may possess ability to promote plant growth by synthesizing plant hormones such as indole-3-acetic acid (Bastian et al., 1998; Gaiero et al., 2013), solubilize phosphate, secrete siderophores, and confers plant tolerance to biotic and abiotic stresses (Shittu et al., 2009; Rybakova et al., 2016). In addition, some bacterial endophytes have the ability to fix atmospheric nitrogen (Santi et al., 2013). However, by their activities in the host, endophytes have created much interest in research geared towards how such organisms could be utilized to enhance global food security and for health and industrial uses. Generally speaking, most plants contain one or more endophytes at some point in their life span. It is noteworthy that, of the nearly 3,000,000 plant species that exist on the earth, each individual plant is the host to one or more endophytes (Strobel et al., 2004). Pathogenic microorganisms after a long period of coevolution with the host plant reach an equilibrium during which they become endophytic; a once pathogenic association between plants and microorganisms can become mutualistic (Xu et al., 2014).

Colonization of host by endophyte when visualized with the use of the b-glucuronidase (GUS) reporter system in rice (Oryza sativa L.) showed high colonization on coleoptiles, lateral roots, and also at some of the junctions of the main and lateral roots (James et al., 2002; Ryan et al., 2008) indicating that endophytes entered the roots through cracks at the point of lateral root emergence and the endophyte subsequently colonized the root intercellular 
168

spaces, and cortical cells, with a few penetrating the stele to enter the vascular tissue.

Endophytes are associated with various tissues and organs of terrestrial and some aquatic plants (Gao et al., 2010). Although endophytes can occur in different parts of a plant, they are usually concentrated in the root (Miliute $e t$ al., 2015). The population density of endophytic bacteria range from $10^{2}$ to $10^{9}$ and depends on many factors, including the plant being studied, the part under analysis, the developmental stage of the plant, the plant cultivar and the interaction with other organisms, as well as other environment-related factors (Costa et al., 2012). Soil conditions (texture, salinity and moisture) are important in the performance of endophytes. It has been suggested that endophytes have specific conditions in which they function optimally. Therefore, the geographical location of the plant is important for commercial use of endophytes. Endophytes could be obligate, facultative or passive depending on if they require plant tissue to live and reproduce. Obligate endophytic bacteria are derived from seeds and cannot survive in soils. Facultative endophytic bacteria widely exist in soil and rhizosphere; they carry out colonization and infection when conditions are suitable. Endophytic bacteria spread across many phyla, which include the Actinobacteria, Bacteroidetes, Firmicutes and Proteobacteria (Hardoim et al., 2015; Wemheuer et al., 2017). Some specific species include Burkholderia phytofirmans, Populus deltoids, Dactylis glomerata, Festuca rubra, Herbaspirillum sp., Lolium perenne, Klebsiella sp., Gluconacetobacter diazotrophicus, Azoarcus sp., Pseudomonas sp. and Klebsiella variicola.

\section{How Endophytic Bacteria Colonize Host Plants}

The term endophytic colonization refers to the way in which endophyte populations enter, grow and multiply within the host plant (Kandel et al., 2017). The source of endophytic colonization ranges from transmission via seeds and vegetative planting material to entrance from the surrounding environment such as the rhizosphere and phyllosphere (Lata et al., 2018). The way in which endophytic bacteria colonize their host plants is systemic. According to the account given by Kandel et al. (2017), it starts from the recruitment of the endophytic bacteria by the host plant. This recruitment procedure is brought about by the release of some exudates such as amino acids, proteins and organic acids from the roots of the host. These exudates play vital roles in the recruitment process by influencing the microbial communities in the rhizosphere, facilitating communication between the host plant and endophytic bacteria (Kawasaki $e t$ al., 2016). There have been several reports on positive correlation of root exudates such as oxalate with increased endophytic bacterial recruitment (Kawasaki et al., 2016; Pétriacq et al., 2017). There are several factors affecting recruitment process of endophytic bacteria by host plants. Some of these factors include bacterial quorum sensing compounds, native soil composition, environmental conditions such as soil nutrition, moisture, temperature, host genotype and age (Zúñiga et al., 2013).

Once the bacterial endophytes are recruited, they swim approximately the root exudates and are attached to the root surface of the host plants. Studies such as the one carried out by Balsanelli and coworkers (2013) implicated exo-polysaccharides (EPS) synthesized by bacterial cells may facilitate the way in which the bacterial cells get attached onto the root surface (rhizoplane). The endophytes explore the potential entry sites to access the internal plant tissue. The main entry sites through which endophytic bacteria enter the internal plant tissues of host plants include areas where root hairs or lateral roots emerged, root apex, stomata or other openings caused by wounds or mechanical injuries as well as hydathodes in the shoots (Hardoim et al., 2015). Researches have also shown that some bacterial endophytes may affect host cell wall by the secretion of cellulolytic enzymes such as pectinase, xylanase and endoglucanase to facilitate easy entry and spread within the plant tissues (Compant et al., 2005; Piromyou et al., 2015). Once inside the host plant, their spread in the root cortex and vascular tissues of host follow, where they occupy the intercellular spaces in the plant because of the abundance of organic and inorganic nutrients in these areas. It has been observed that colonization can be localized at the tissue level or spread systemically throughout the plant body (Glassner, 2017).

\section{Molecular Identification and Characterization of Endophytic Bacteria Associated With Plants}

For research purpose and other applications, endophytic bacteria have been isolated and characterized from different plants and plant - parts. There have been reports on isolation from leaf and root of Eichornia crassipes [Mart.] Solms. (Gherbawy and Hassan, 2012) and root nodules (Tariq et al., 2014). Bacterial endophytes such as species of Burkholderia, Methylobacterium, Sphingomonas, and Pantoea have been isolated from grape plants. Members of the phyla Proteobacteria, Actinobacteria, Verrucomicrobia and Acidobacteria have been isolated from tomato (Solanum lycopersicum L.) leaves (Romero et al., 2014). Also, Bacillus, Delftia, Methylobacterium, Microbacterium, Paenibacillus, Staphylococcus and Stenotrophomonas have been reported to be isolated from bean (Phaseolus vulgaris) leaves (Costa et al., 2012).

Conventionally, plant part is first washed, surface sterilized and rinsed with sterile double distilled water. The plant part is cut into small pieces, aseptically transferred onto an appropriate growth medium and the culture is incubated at optimal temperature. Bacterial colonies appear after 24 hour and the colonies are sub-cultured individually onto fresh growth media to obtain pure cultures of the isolates. A preliminary phenotypic identification is carried out (Cullimore, 2000) which is followed by biochemical characterization for separating isolates into morphotypes.

In recent times, culture-independent methods are now used to identify and characterize many endophytes. These approaches include sequencing of the 16S rRNA gene (for endophytic bacteria), the internal transcribed spacer regions, ITS1 and ITS2 (for endophytic fungi), or through whole genome sequencing of endophyte communities (metagenomics) (Turner et al., 2013; Sessitsch et al., 2013). Using this approach, genomic DNA is isolated from a pure culture of an endophytic bacterium. The nucleic acid extraction can be carried out by the use of either an efficient and well-optimized laboratory protocol or bacterial DNA 
extraction kits, following the manufacturer's instructions. A specific DNA sequence in the bacterial genome, 16S ribosomal RNA (rRNA) gene, which is relatively short, that is often conserved within a species, and generally different between species is usually targeted in a polymerase chain reaction (PCR) amplification. The $16 \mathrm{~S}$ ribosomal RNA, a component of the $30 \mathrm{~S}$ small subunit of all prokaryotic ribosomes has become the segment of choice because it is highly conserved between different species of bacteria and, as such, it is usually used in phylogenetic studies (Cole et al., 2003). Also, the $16 \mathrm{~S}$ rRNA gene sequences contain hypervariable regions that can provide species specific signature sequences, which has made it useful for bacterial identification (Smit et al., 2007).

For molecular identification, there are different strategies used. Bacterial universal primers are designed to target the $16 \mathrm{~S}$ region of the rRNA gene and synthesized. The primer pair is used for PCR amplification with the endophytic bacterial genomic DNA as template. The PCR amplified fragment is purified and sequenced. The nucleotide sequence is compared with consensus sequence data from public databases such as the National Center for Biotechnology Information (NCBI) or European Nucleotide Archive (ENA) by using the BLAST $N$ sequence match routine. The best hit usually reveals the identity of the isolate. This molecular identification procedure is so powerful that it could be used to reveal the identity of a bacterial isolate up to the sub species level. The second strategy involves designing a pair of species-specific primers, which are used for a PCR amplification of the nucleic acid isolated from test endophytic bacterial isolate. Appearance of a band on the gel electrophoresis indicates that the isolate is the species for which the primers were designed. This method of molecular identification is often used more or less for a confirmatory purpose.

\section{Plant Protection Induced by Endophytic Bacteria}

Plants in their natural or artificial environments are often faced with different stresses, which are broadly classified into biotic and abiotic (non-biotic) stresses. Biotic stress is due to living organisms usually pathogens or competitors that compete for growth factors such as nutrients, space and water. Common sources of biotic stress are fungi, nematodes, viruses, insects and bacteria. Abiotic stress refers to those non-biological factors such as environmental and chemical that may lead to decrease in plant productivity. The abiotic stress from which plants may suffer include drought, temperature extremities, acidic or alkaline $\mathrm{pH}$ conditions, heavy metal contamination, extreme salinity levels and nutrient deficiency. Biotic and non-biotic stresses can lead to huge economic losses occasioned by crop damage if plants are not protected against them. Research has indicated that endophytes offer great protection against these stresses.

\section{Bacterial Endophyte-Induced Plant Protection against Biotic Stress}

Biotic stress is caused by living components of the external and internal environment of plants. Crop losses due to pathogenic organisms may amount to billions of US dollars annually (Cocq et al., 2017). The common and fastest method of plant disease control is by the use of chemicals and this has adverse effects on the ecosystem.
Endophytes have been found to confer some protection on their hosts against invading pathogens. Endophytic microbiome constitutes a part of larger soil microbial community and is susceptible to direct or indirect effect of agricultural practices: soil tillage, irrigation, use of pesticides and fertilizers has a major effect on function and structure of soil and endophytic microbial populations (Tamosiune $e t$ al., 2017).

Fungi are responsible for most plant diseases (Idnurm and Meyer, 2014). Endophytic bacteria have been found to have the ability to protect their host plants against certain pathogenic fungi. Endophytic bacteria including Aureobacterium, Bacillus, Paenibacillus, Phyllobacterium, Pseudomonas, and Burkholderia recovered from host plants or seeds showed antagonistic activities against the plant pathogens Fusarium oxysporum, Rhizoctonia solani, Sclerotium rolfsii, Verticillium dablia and many other fungi (Rybakova et al., 2016). Maize plants inoculated with endophytic Enterobacter aerogenes that produce volatile organic compounds showed enhanced resistance against the northern corn leaf blight caused by the fungus Setosphaeria turcica (D'Alessandro et al., 2014). The endophytic Pseudomonas poae strain RE*1-1-14 isolated from sugar beet roots was found to suppress the fungal pathogen, Rhizoctonia solani (Zachow et al., 2015). Streptomyces SUK 06 produces antifungal activity against Fusarium solani, Aspergillus fumigatus, Pythium ultimum, Phytophthora erythroseptica and Geothrichum candidum (Ghadin et al., 2008). In addition, a strain of Streptomyces mutabilis has been found useful in the control of the fungal pathogen, Fusarium culmorumin in wheat.

Information on the antiviral properties of endophytic bacteria is still scanty. The case of plant viruses is different from other pathogens because viruses are affected by the host plant metabolites as well as the outcome of the interaction between plant and insect vectors that transmit the viruses. Although with only few examples, endophytes protect their host plants against pathogenic viruses. For example, the barley yellow dwarf virus (BYDV) transmitted by aphids; alkaloids produced by endophytes repel aphids (Lehtonen et al., 2006).

Endophytic bacteria also have the capability of protecting plants against pathogenic bacteria. Research has shown that Streptomyces SUK 06 isolated from Thottea grandiflorahas bactericidal effect on Bacillus subtilis, Pseudomonas aeruginosa, Bacillus cereus and Pleisiomonas shigelloides. In addition, there are reports on metabolites produced by some endophytic bacteria, which prevent the host plants from infection by nematodes (Hallmann et al., 1998). Some metabolites produced by endophytes prevent the host plant from infection by insects (Azevedo et al., 2000). During drought conditions, endophytes stimulate the production of more alkaloids, which confers protection against herbivory arising from insects and other arthropods. Because of this, there will be a reduction in insect population and consequently, a decrease in disease occurrence. Nodulisporic acids originally isolated from the endophyte Nodulisporium sp., from the plant Bontia daphnoides have insecticidal properties against blowfly larvae. This finding has prompted further research on sources of these acids (Demain, 2000). 
170

Bacterial Endophyte-Induced Plant Protection against Abiotic Stress

Inadequate nutrient supplies alter the growth, development and general physiology of the plant. In the case of drought, the plant suffers insufficient water availability caused by excessive loss of water and/or inadequate supplies, which can lead to toxic ion and unfavourable salinity and $\mathrm{pH}$ levels. Under water stress, photosynthesis, soluble proteins, dry weight and carotenoids tend to decrease in some plants that have low threshold for water stress. Prolonged water stress causes decline in leaf water potential and stomatal opening, reduces leaf size, suppresses root growth, reduces seed number, size and viability, delays flowering and fruiting, and limits plant growth and productivity (Xu et al., 2016). Osmotic imbalance results from high salinity while post-optimal temperatures denature enzymes, making them inactive. On the other hand, extremely low temperatures retard metabolic activities. Accumulation of heavy metals causes a disruption of the normal metabolic pathways.

Apart from protecting plant from diseases, endophytes also help in the survival of plants under various environmental conditions. Experiments have shown that survival rate due to endophytes could be as high as six-fold compared to plants without endophytes. Endophytic microbes aid in plant health by deterring pathogenesis while also facilitating plant growth through nutrient uptake (modification of root morphology, alteration of nitrogen accumulation and metabolism), water-use efficiency (osmotic adjustment, stomatal regulation) and curtailing of environmental stresses. The endophytes, in return, obtain access to the host plant's nutrients and dissemination to the next generation. Endophyte-induced protection of host plant occurs by the endophytes enabling nutrient supplies, increasing salt and acidity tolerance (by removal of reactive oxygen species) and by increasing heat and heavy metal tolerance (Lata et al., 2018). When temperatures increase, the host becomes more susceptible while viral populations increase, thereby increasing disease severity.

\section{Mechanisms of Plant Protection by Endophytic Bacteria}

Information on the mechanisms by which endophytes protect their host plants from invasion and colonization by pathogens is not yet definitive. However, results of previous in vitro studies point to two major ways; direct means (production of chemicals which kill or prevent pathogens) or indirectly, by inciting the host to defend itself by the several available mechanisms.

Direct Mechanism that Antagonizes Plant
Pathogens
Production of antibiotics: Some secondary metabolites
serve as antibacterial and antifungal agents against
pathogens. Examples are alkaloids, terpenoids, phenolic
substances, polypeptides and sesquiterpenes (Gunatilaka,
2006). Several rhizosphere - inhabiting bacteria that often
become endophytes, stimulate the production of these
metabolites by their hosts while they themselves also
produce some. Examples of such bacteria are species
of Bacillus and Pseudomonas. A number of metabolites,
particularly lipopeptides synthesized by non-ribosomal

peptide synthesizes, have been described to be important for rhizosphere bacteria for antibiosis and for inducing plant defense mechanisms.

Production of hydrolytic enzymes: The role of hydrolytic enzymes may be multifaceted, involving several mechanisms working together; the enzymes could kill the pathogen cells, trigger the strengthening of host cell wall to resist infections, or induce apoptosis. These mechanisms need further investigations. Hydrolytic enzymes disrupt the structural organization of the cell wall components, causing a degradation of the cell wall. Structural components of cell wall include cellulose, hemicelluloses, lignin, chitin and certain proteins. Therefore, endophytes produce enzymes which breakdown cell walls of fungal pathogens of the host plants, and by so doing, they suppress the growth and advancement of pathogen. Hydrolytic enzymes produced by Streptomyces enhance the resistance of cocoa plant to the witches' broom pathogen. Examples of hydrolytic enzymes are 1, 3-glucanases, chiti-nases and cellulases (Gao et al., 2010).

Indirect Mechanisms That Improve Resistance of Host to Pathogens

Endophytes indirectly enhance the host resistance against invading pathogens by various ways. The resultant resistance mechanism could be structural or biochemical. Changes in the environment (like fluctuations in temperature and salinity as well as drought, heavy metal ions, UV light and presence of pathogen) can lead to stress in plants. Consequently, the plant responds in various ways among which are biochemical and structural (morphological) changes. Research over the years has shown that non- specific and specific resistance (Kloepper and Ryu, 2006; Kiraly et al., 2007) come into play. Mechanisms which endophytes increase host may group plant resistance as follows.

Production of metabolites: Specific resistance targets smaller number of pathogens or specific pathogens. Since endophytes behave like pathogens (except that endophytes do not elicit disease symptoms) by their activities such as stimulating the host plant to produce secondary metabolites (like phytoalexins) and triggering hypersensitive reactions (that lead to death of affected host cells in a bid to stop the spread of pathogen), they increase the host plant resistance to disease. Endophytes can ameliorate the effect of stress by reducing the expression of stress genes or by production of chemical substances that act to neutralize the effect of stress. For example, experimental Arthrobacter and Bacillus species isolated from pepper plant showed up-regulation and downregulation of stress-inducible genes compared with gene expression in uninoculated plants (Lata et al., 2018). Alterations in the levels of 1-aminocyclopropanecarboxylate (ACC) by Pseudomonas can bring about heavy metal tolerance through changes in ethylene levels in plants.

Enzymatic activities: In addition, systemic acquired resistance (SAR) which is induced by presence of pathogen leads to accumulation of pathogenesis-related (PR) proteins and these proteins are made up of different enzymes such as peroxidases (Tian et al., 2008). It is suggested that peroxidases could reduce damage from reactive oxygen species (ROS) which accompanies infection and high salinity and alkalinity levels; endophytes indirectly increase 
the levels of antioxidants which remove the ROS (Alquéres et al., 2010). The ROS-scavenging enzymes are reported to be involved in the biological nitrogen fixation of Gluconacetobacter diazotrophicus and are essential for its successful colonization in endophytic rice roots (Alquéres et al., 2010).

Accumulation of complex structural polymers: In response to the presence of endophyte, the host pant produces hydrolytic enzymes that release endophyte metabolites such as lipopolysaccharides, polysaccharides and glycoproteins; these endophyte metabolites in addition to host plant metabolites enhance plant defence against pathogen attack. Endophytes confer drought tolerance by accumulation of solutes in host plant tissues and by reducing transpiration. For instance, endophytes could induce formation of thick cuticle that minimizes loss of water.

Increased plant nutrition: The amount of iron available in the soil is usually limited. Therefore, the production of siderophores by an organism is of advantage because the siderophores chelate iron in the soil and form soluble complexes that the plants can absorb. More siderophores are produced when endophytes are present. In addition, siderophores are involved in plant protection as they deprive phytopathogens of iron by binding to the bioavailable forms of iron first (Aznar et al., 2015). Some bacteria fix nitrogen for the host plant especially leaf-inhabiting bacteria. The nitrogen-fixing bacterium Paenibacillus polymyxa promotes growth in maize.

Control of growth and physiology of host plant: Interactions between endophyte and host lead to the production of bioactive molecules (Heinig et al., 2013) such as growth regulatory hormones. Production of plant hormones may enhance or suppress plant growth depending on which one is advantageous to it in the presence of a pathogen. It has been demonstrated that endophytes promote growth of their host through the action of plant hormones produced by the endophytes (Abadi and Sepehri, 2015). It could also be by other means such as nitrogen fixation, release of ions or mediation by enzymes. For example, ethylene, a plant growth suppressant is largely deactivated by certain deaminases, thereby indirectly promoting growth. When endophytes promote growth in their host, stress is significantly reduced. Piriformospora indica and Azotobacter chroococcum improve uptake of zinc in wheat (Abadi and Sepehri, 2015). Nitrogen-fixing bacteria produce nutrients for the plant that aid plant growth.

Creation of ecological niche: After recognizing and colonizing their host, endophytes rapidly occupy ecological niche and leave no space for pathogens, which would be the common and main reason that endophytes inhibit pathogen infection in plant (Gao et al., 2010). In the endophytic niche, endophytes feed on nutrients from the plants and prevent other organisms by outcompeting them. Moreover, there is increased production of lignin and other complex components of the cell wall aimed at regulating the growth of the endophyte so that it does not grow to the extent of being pathogenic; deposition of these complex materials in the cell wall reduces the ease of entry of pathogens.
Parasitism and predation: Another mechanism by which endophytes protect their hosts is to kill the pathogen outright (predation) or parasitize it by twisting, penetrating the hyphae of pathogen and secreting lyase to decompose cell wall of the pathogen (Gao et al., 2010). This attribute of endophyte is exploited for the biological control of pathogens.

\section{Global Gene Expression Studies in Endophyte- Induced Plant Protection}

In plant-pathogen interactions, phytopathogens have evolved astonishingly myriad invasion strategies to attack plants for food and shelter (Shittu et al., 2017), while on the other end of the spectrum, host plants also deploy numerous structural and biochemical defence mechanisms to prevent or ameliorate the effects of phytopathogens (Shittu and Obiazikwor, 2018). The outcome of such interactions leading to susceptibility, tolerance or resistance are determined by a well-coordinated level of up- or downregulations of defense genes, including pathogenesis related (PR) genes in host plants. One of the beneficial effects of an endophytic bacterium is the ability to offer protection to host plants against pathogen attack. The mechanism underlying such endophyte - induced plant protection lies in the expression of certain genes in host plants. Global gene expression analysis has revealed that endophytic microbes may stimulate plant growth and mobilize plant defenses that selectively target phytopathogens. In a study carried out by Shittu and coworkers (2009), an up regulation of the genes for $\beta$-carotene hydroxylase, Rubisco and glutamyltRNA synthase indicated an increase in photosynthetic activity in endophyte-induced protected plants, which is likely to result in an increased vigor and a stronger resistance response against pathogen.

Endophytes that colonize plant vascular systems induce PR proteins (Van Loon, 2006) associated with SAR or SIR responses in plants (Tjamos et al., 2005). In plant-pathogen interactions, one of the early responses of plants is frequent release of signaling molecules; salicylic acid (SA) and jasmonic acid (JA), which have been implicated to be involved in induction of defense gene expression (Mur et al., 2006; Vlot et al., 2009). The expression of such genes induces plant defence pathways, which makes the host to become more resistant to further pathogen attack (Ongena and Thonart, 2006; Van Loon and Bakker, 2006), a phenomenon often referred to as induced systemic resistance (ISR). There are several reports on endophyteinduced gene expression leading to plant protection. An example is the endophytic action bacteria, which were isolated from wheat tissues that up-regulated defense genes like PR- 1 and $P R-4$ of SAR as well as PDF1.2 and $\mathrm{Hel}$ genes of the jasmonic acid/ethylene (JA/ET) pathway in Arabidopsis thaliana (Conn et al., 2008).

Whole Genome Sequencing in Endophyte Research

An interesting question that bothers a curious mind is 'of what importance is whole genome sequencing in endophyte research'? The results obtained from genomic dataset of endophytic bacterial strains are valuable repository of information that provides insights into the taxonomy, distribution, diversity, and lifestyle related genes 
172

of endophyte associated with host plants (Chaudhry et al., 2017). Our understanding of the beneficial effects of endophytes in the crucial roles they play in plant growth, development, fitness, and protection (Taghavi et al., 2010; Truyens et al., 2014) has increased during the post-genomic era, which ushered in whole genome sequencing of several agriculturally important crop plants and microbes (Shittu, 2012), including endophytes. The molecular basis underlying such interactions has been partially or fully elucidated. Structural and functional analysis of whole genome sequences reveal that bacterial endophytes possess genes that encode information required for their housekeeping machinery as well as growth under a range of favourable and unfavourable conditions, irrespective of the habitat of the host plants. In addition, their genomes also contain genes necessary to carry out endophytic life style and plant beneficial properties.

Burkholderia sp. strain KJ006, an endophytic bacterium associated with rice root bacterial strain benefits its host plant by providing plant growth substances and a broad range of antifungal activities but does not exhibit any symptoms related to pathogenicity (Cho et al., 2007). An insight into the whole genome sequence of the strain (Kwak, 2012) revealed that the $6.6 \mathrm{Mb}$ genome, consisting of three chromosomes and a single plasmid, contains several genes related to plant growth promotion and antimicrobial activities. Expression of such plant growth promotion genes, such as the $\mathrm{accD}$ gene, encoding 1-aminocyclopropane-1carboxylate deaminase; the pqq operon for pyrroloquinoline quinone biosynthesis, and the nif gene cluster enhances growth. Strain KJ006 also contains the homoserine lactonase gene of Bacillus thuringiensis, whose expression represses the seedling rot disease caused by Burkholderia glumae (Cho et al., 2007). It has also been discovered that the genome also harbors genes related to degradation of several kinds of aromatic pollutants (Perez-Pantoja et al., 2012). A similar whole genome analysis report has been made on some endophytic Bacillus species having genes that enable them play important roles as a biocontrol agent against phytopathogens, stimulate plant growth, and also produce plant growth hormones such as auxin and gibberellin, as well as able to ameliorate drought stress (Forchetti et al., 2007). Some endophytic bacteria whose genomes have been sequenced include: eleven endophytic bacteria isolated from Poison Ivy (Toxicodendron radicans) (Tran et al., 2015), an endophytic bacterium Enterobacter sp. MR1, isolated from drought tolerant plant (Buteamonosperma) (Parakhia et al., 2014) and an endophytic bacterium isolated from poplar trees (Taghavi $e t$ al., 2009).

\section{Conclusions}

Endophytic bacteria present in the internal tissues of a host plant live with the plant as it undergoes different developmental phases such as vegetative and reproductive stages, thereby posing as hidden companions of the host plant. This relationship offers the endophytic bacteria shelter and nutrient supply. In return, the host plant benefits from the endophyte by gaining protection against biotic and abiotic stresses that would otherwise hinder the host's proper physiological functioning. There is much to be gained from this relationship between endophytic bacteria and their host plants; this can be applied in the areas of agriculture, medicine, industry and environment, if properly harnessed.

\section{Conflicts of interest}

The authors declare that there are no conflicts of interest related to this article.

\section{References}

Abadi VAJ, Sepehri M (2015). Effect of Piriformospora indica and Azotobacter chroococcum on mitigation of zinc deficiency stress in wheat (Triticum aestivum L).)Symbiosis 69(1):9-19.

Alquéres SM, OliveiraJH, Nogueira EM, Guedes HV, Oliveira PL, Câmara $\mathrm{F}$,.... Martins $\mathrm{OB}$ (2010). Antioxidant pathways are up-regulated during biological nitrogen fixation to prevent ROS-induced nitrogenase inhibition in Gluconacetobacter diazotrophicus. Archives of Microbiology 192(10):835-841.

Azevedo JL, Maccheroni J, Jr. Pereira O, Ara WL (2000). Endophytic microorganisms: a review on insect control and recent advances on tropical plants. Electronic Journal of Biotechnology 3(1):15-16.

Aznar A, Chen NW, Thomine S, Dellagi A (2015).Immunity to plant pathogens and iron homeostasis. Plant Science 240:90-97.

Balsanelli E, Tuleski TR, de Baura VA, Yates MG, Chubatsu LS, de Oliveira PF, de Souza EM, Monteiro RA (2013). Maize root lectins mediate the Interaction with Herbaspirillum seropedicae via N-Acetyl gucosamine residues oflipopolysaccharides. PLoS ONE 8(10):e77001.

Bastian F, Cohen A, Piccoli P, Luna V, Baraldi R, Bottini R (1998). Production of indole-3-acetic acid and gibberellins $\mathrm{A} 1$ and $\mathrm{A} 3$ by Acetobacter diazotrophicus and Herbaspirillum seropedicae in chemicallydefined culture media. Plant Growth Regulator 24(1):7-11.

Beltran-Garcia MJ, White JF Jr, Prado FM, Prieto KR, Yamaguchi LF, Torres MS, ... Di Mascio P (2014). Nitrogen acquisition in Agave tequilana from degradation of endophytic bacteria. Scientific Reports 4:6938.

Chaudhry V, Sharma S, Bansal K, Patil PB (2017). Glimpse into the genomes of rice endophytic bacteria: Diversity and distribution of firmicutes. Frontiersin Microbiology 7:2115.

Cho HS (2007). Interference of quorum sensing and virulence of the rice pathogen Burkholderia glumae by an engineered endophytic bacterium. FEMSMicrobiology Ecology 60(1):1423.

Cocq K, Gurr SJ, Hirsch PR, Mauchline TH (2017). Exploitation of endophytes for sustainable agricultural intensification. Molecular Plant Pathology 18(3):469-473.

Cole JR, Chai B, Marsh TL, Farris RJ, Wang Q, Kulam SA, ... Chandra S (2003). The Ribosomal Database Project (RDP-II): previewing a new autoaligner that allows regular updates and the new prokaryotic taxonomy.Nucleic Acids Research 31(1):442-443.

Compant S, Reiter B, Nowak J, Sessitsch A, Clément C, Barka EA (2005). Endophytic colonization of Vitis vinifera $\mathrm{L}$. by plant growth-promoting bacterium Burkholderia sp. Strain PsIN. Applied Environmental Microbiology 71(4):1685-1693.

Conn V, Walker A, Franco CM (2008). Endophytic actinobacteria induce 
defense pathways in Arabidopsis thaliana. Molecular Plant Microbe Interaction 21(2):208-218.

Costa LEO, Queiroz MV, Borges AC, Moraes CA, Araújo EF (2012). Isolation and characterization of endophytic bacteria from the leaves of common bean (Phaseolus vulgaris). Brazilian Journal of Microbiology 43(4):1562-1575.

Cullimore DR (2000). Practical atlas for bacterial identification. Florida; CRC Press, Florida pp 209.

D’Alessandro M,ErbM, Ton J, BrandenburgA, Karlen D,Zopfi J, Turlings TCJ (2014). Volatiles produced by soil-borne endophytic bacteria increase plant pathogen resistance and affect tritrophic interactions. Plant, Cell and Environment 37(4):813-826.

Demain AL (2000). Microbial natural products: A past with a future. In: Wrigley SK, Hayes MA, Thomas R, Chrystal EJT, Nicholson N (Eds). Biodiversity: New Leads for Pharmaceutical and Agrochemical Industries. The Royal Society of Chemistry, Cambridge, United Kingdompp3-16.

Forchetti G, Masciarelli O, Alemano S, Alvarez D, Abdala G (2007). Endophytic bacteria in sunflower (Helianthus annuus L.): isolation, characterization, and production of jasmonates and abscisic acid in culture medium. Applied Microbiology and Biotechnology 76(5):1145-1152.

Gaiero JR, McCall CA, Thompson KA, Day NJ, Best AS, Dunfield KE (2013). Inside the root microbiome: Bacterial root endophytes and plant growth promotion. American Journal of Botany 100(9):17381750.

Gao F, Dai C, Liu X (2010). Mechanisms of fungal endophytes in plant protection against pathogens. African Journal of Microbiology Research 4(13):1346-1351.

Ghadin N, Zin NM, Sabaratnam V, Badya N, Basri DF, Lian HH, Sidik $\mathrm{NM}(2008)$. Isolation and characterization of a novel endophytic Streptomyces SUK 06 with antimicrobial activity from Malaysian plant. Asian Journal of Plant Science 7(2):189-194.

Gherbawy Y, Hassan S (2012). Molecular characterization of endophytic bacteria from metal hyperaccumulator aquatic plant (Eichhornia crassipes) and its role in heavy metal removal. Geomicrobiology Journal 29(10):906-915.

Glassner H, Zchori-Fein E, Yaron S, Sessitsch A, Sauer U, Compant S (2017). Bacterial niches inside seeds of Cucumis melo L. Plant and Soil 422(1-2):101-113.

Gunatilaka AAL (2006). Natural products from plant-associated microorganisms: distribution, structural diversity, bioactivity and implications of their occurrence. Journal of Natural Product 69(3):509526.

Hallmann J, Quadt-Hallmann A, Rodriguez-Kabana R, Kloepper JW (1998). Interactions between Meloidogye incognita and endophytic bacteria in cotton and cucumber. Soil Biology and Biochemistry 30(7):925-937.

Hardoim PR, van Overbeek LS, Berg G, Pirttilä AM, Compant S, Campisano A, ... Sessitsch A (2015). The hidden world within plants: Ecological and evolutionary considerations for defining functioning of microbial endophytes. Microbiology and Molecular Biology Reviews 79(3):293-320.
Heinig U, Scholz S, Jennewein S (2013). Getting to the bottom of taxol biosynthesis by fungi. Fungal Diversity 60(1):161-170.

Idnurm A, Meyer V (2014). Welcome to fungal biology and biotechnology. Fungal Biology and Biotechnology 1:8.

James EK, Gyaneshwar P, Mathan N, Barraquio WL, Reddy PM, Iannetta PP, ... Ladha JK (2002). Infection and colonization of rice seedlings by the plant growth-promoting bacterium Herbaspirillum seropedicae Z67. Molecular Plant Microbe Interaction 15(9):894-906.

Kandel SL, Joubert PM, Doty SL (2017). Bacterial endophyte colonization and distribution within plants. Microorganisms 5:77.

Kawasaki A, Donn S, Ryan PR, Mathesius U, Devilla R, Jones A, Watt M (2016). Microbiome and exudates of the root and rhizosphere of Brachypodium distachyon, a model for wheat. PLoS One 11:e0164533.

Kiraly L, Barna B, Kiraly Z (2007). Plant resistance to pathogen infection: forms and mechanisms of innate and acquired resistance. Journal of Phytopathology 155(7-8):385-396.

Kloepper JW, Ryu CM (2006). Bacterial endophytes as elicitors of induced systemic resistance. In: Schulz BJE, Boyle CJC, Sieber TN (Eds). Microbial Root Endophytes. Springer-Verlag, Berlin pp 33-52.

Kwak M (2012). Complete genome sequence of the endophytic bacterium Burkholderia sp. strain KJ006. Journal of Bacteriology 194(16):44324433.

Lata R, Chowdhury S, Gond SK, White Jr.JF (2018). Induction of abiotic stress tolerance in plants by endophytic microbes. Letters in Applied Microbiology 66(4):268-276.

Lehtonen PT, Helander M, Siddiqui SA, Lehto K, Saikkonen K (2006). Endophytic fungus decreases plant virus infections in meadow ryegrass (Lolium pratense). Biology Letters 2(4):620-623.

Miliute I, Buzaite O, Baniulis D, Stanys V (2015). Bacterial endophytes in agricultural crops and their role in stress tolerance: a review. Zemdirbyste-Agriculture 102(4):465-478.

Parakhia MV, Tomar RS, Malaviya BJ, Dhingani RM, Rathod VM, ... Golakiya BA (2014). Draft genome sequence of the endophytic bacterium Enterobacter sp. MR1, isolated from drought tolerant plant (Buteamonosperma). Indian Journal of Microbiology 54(1):118-119.

Perez-Pantoja D, Donoso R, Agullo L, Cordova M, Seeger M, Pieper DH, Gonzalez B(2012). Genomic analysis of the potential for aromatic compounds biodegradation in Burkholderiales. Environmental Microbiology 14(5):1091-1117.

Petriacq P, Williams A, Cotton A, McFarlane AE, Rolfe SA, Ton J (2017). Metabolite profiling of non-sterile rhizosphere soil. The Plant Journal 92(1):147-162.

Piromyou P, Songwattana P, Greetatorn, T, Okubo T, Kakizaki KC, Prakamhang J, ... Minamisawa K (2015). The type III secretion system (T3SS) is a determinant for rice-endophyte colonization by nonphotosynthetic Bradyrhizobium. Microbes and Environment 30:291300.

Romero FM, Marina M, Pieckenstain FL (2014). The communities of tomato (Solanum lycopersicum L.) leaf endophytic bacteria, analyzed by 16S-ribosomal RNA gene pyrosequencing. FEMS Microbiology Letters 351:187-219.

Ryan RP, Germaine K, Franks A, Ryan DJ, Dowling DN (2008). Bacterial endophytes: recent developments and applications. FEMS 
174

Microbiology Letters 278(1):1-9.

Rybakova D, Cernava T, Köberl M, Liebminger S, Etemadi M, Berg G (2016). Endophytes-assisted biocontrol: novel insights in ecology and the mode of action of Paenibacillus. Plant and Soil 405(1-2):125-140.

Santi C, Bogusz D, Franche C (2013). Biological nitrogen fixation in nonlegume plants. Annals of Botany 111(5):743-767.

Sessitsch A, Hardoim P, Döring J, Weilharter A, Krause A, Woyke T, ... Rahalkar M (2012). Functional characteristics of an endophyte community colonizing rice roots as revealed by metagenomic analysis. Molecular Plant Microbe Interactions 25(1):28-36.

Shittu HO, Castroverde DMC, Nazar RN, Robb J (2009). Plantendophyte interplay protects tomato against a virulent Verticillium. Planta 229(2):415-426.

Shittu HO (2012). The concept of genomics: A review. Nigerian Journal of Botany 25(1):79-92.

Shittu HO, Aghogban ON, Igiehon E (2017). Plant pathogen attack strategies. Journal of Phytopathology and Plant Health 4(1):1-9.

Shittu HO, Obiazikwor OH (2018). Arms race between phytopathogens and host plants: A similitude of two nations at war. Journal of Microbiology, Biotechnology and Food Science 7(6):646-650.

SmitS, Widmann J, Knight R (2007). Evolutionary rates vary amongrRNA structural elements. Nucleic Acids Research 35(10):3339-3354.

Strobel G, Daisy B, Castillo U, Harper J (2004). Natural products from endophytic microorganisms. Journal of Natural Product 67(2):257268.

Taghavi S, Garafola C, Monchy S, Newman L, Hoffman A, Weyens N, ... van der Lelie D (2009). Genome survey and characterization of endophytic bacteria exhibiting a beneficial effect on growth and development of poplar trees. Applied and Environmental Microbiology 75(3):748-757.

Taghavi S, Van Der Lelie D, Hoffman A, Zhang YB, Walla MD, Vangronsveld J, ... Monchy S (2010). Genome sequence of the plant growth promoting endophytic bacterium Enterobacter sp. 638. PLoS Genetics 6:e1000943.

Tariq M, Zahid M, Hameed S, Zafar M, Yasmeen T (2014). Molecular characterization and identification of plant growth promoting endophytic bacteria isolated from the root nodules of pea (Pisum sativum L.). World Journal of Microbiology and Biotechnology 30(2):719-725.

Tamosiune I, Baniulis D, Stanys V (2017). Role of endophytic bacteria in stress tolerance of agricultural plants: Diversity of microorganisms and molecular mechanisms. In: Kumar V, Kumar M, Sharma S, Prasad R (Eds). Probiotics in Agroecosystem. Springer, Singapore pp 26-42.
Tian P, Nan Z, Li C (2008). Effect of the endophyte Neotyphodium lolii on susceptibility and host physiological response of perennial ryegrass to fungal pathogens. European Journal of Plant Pathology 122(4):593602.

Tjamos SE, Flemetakis E, Paplomatas EJ, Katinakis P (2005). Induction of resistance to Verticillium dabliae in Arabidopsis thaliana by the biocontrol agent K-165 and pathogenesis-related proteins gene expression. Molecular Plant-Microbe Interaction 18(6):555-561.

Tran PN, Tan NE, Lee YP, Gan HM, Polter SJ, Dailey LK, ... Savka MA (2015). Whole-genome sequence and classification of 11 endophytic bacteria from poison ivy (Toxicodendron radicans). Genome Announcements 3(6):e01319-15.

Truyens S, Weyens N, Cuypers A, Vangronsveld J (2014). Bacterial seed endophytes: genera, vertical transmission and interaction with plants. Environmental Microbiology Reports 7(1):40-50.

Turner TR, James EK, Poole PS (2013). The plant microbiome. Genome Biology 14:209-213.

Van Loon LC (2006). Significance of inducible defense-related proteins in infected plants. Annual Review of Phytopathology 44:135-162.

Wemheuer F, Kaiser K, Karlovsky P, Daniel R, Vidal S, Wemheuer B (2017). Bacterial endophyte communities of three agricultural important grass species differ in their response towards management regimes. Scientific Reports 7:409-414.

Xu XH, Su ZZ, Wang C, Kubicek CP, Feng XX, Mao LJ, ... Zhang CL (2014). The rice endophyte Harpophora oryzae genome reveals evolution from a pathogen to a mutualistic endophyte. Scientific Reports4:5783.

XuZ, Jiang Y,Jia B,Zhou G (2016). Elevated-CO $\mathrm{CO}_{2}$ response of stomata and its dependence on environmental factors. Frontiers in Plant Science 7:657.

Zachow C, Jahanshah G, de Bruijn I, Song C, Ianni F, Pataj Z, ... Gross H (2015). The novel lipopeptide poaeamide of the endophyte Pseudomonas poae RE_1-1-14 is involved in pathogen suppression and root colonization. Molecular Plant Microbe Interactions 28(7):800810.

Zuniga A, Poupin MJ, Donoso R, Ledger T, Guiliani N, Gutiérrez RA, Gonzalez B (2013). Quorum sensing and indole-3-acetic acid degradation play a role in colonization and plant growth promotion of Arabidopsis thaliana by Burkholderia phytofirmans PsIN. Molecular Plant-Microbe Interactions 26(5):546-553. 